\title{
Study of the Determinants of the Population's Membership of Mutual Health Insurance in the Health District of Guédiawaye (Senegal) in 2015
}

\author{
Diop Cheikh Tacko, ${ }^{1, ~ *, ~ M a i ~ I d r i s s ~ M a h a m a t ~}{ }^{2}$, Lo Ahmadou $^{2}$, Ka Ousseynou $^{1}$, Gueye Boubacar ${ }^{1}$, \\ Bop Martial Coly ${ }^{1}$, Faye Adama ${ }^{2}$ \\ ${ }^{1}$ Faculty of Community Health, Alioune DIOP University, Bambey, Senegal \\ ${ }^{2}$ Faculty of Medicine, Pharmacy and Dentistry, Cheikh Anta DIOP University, Dakar, Senegal
}

Email address:

cheikhtackodiop@gmail.com (D. C. Tacko)

*Corresponding author

\section{To cite this article:}

Diop Cheikh Tacko, Mai Idriss Mahamat, Lo Ahmadou, Ka Ousseynou, Gueye Boubacar, Bop Martial Coly, Faye Adama. Study of the Determinants of the Population's Membership of Mutual Health Insurance in the Health District of Guédiawaye (Senegal) in 2015. World Journal of Public Health. Vol. 5, No. 1, 2020, pp. 24-29. doi: 10.11648/j.wjph.20200501.14

Received: January 13, 2020; Accepted: March 2, 2020; Published: March 17, 2020

\begin{abstract}
Financing health care continues to be a major challenge in low-income countries where universal health coverage is still far from being achieved. The objective of our study is to assess the level of adherence of populations to mutual health insurance and to study the determining factors. We conducted a cross-sectional, descriptive and analytical study among a sample of household heads selected through a two-stage cluster survey from 21 to 31 December 2015 in the district of Guédiawaye. A questionnaire validated after a pre-test was administered during an individual interview. Socio-economic and household characteristics, factors related to the provision of care and those related to mutual health insurance were collected. These data were entered and analyzed on Epi Info 2000 version 3.5.3. The significance value was $p<0.05$. The Odds ratio was used to measure the strength of the link. The study covered 300 heads of household, $90 \%$ of whom live in rural areas. The average age was 49.7 years with $93 \%$ of male. The overall membership rate was $16.7 \%$. The analysis showed that UDAM membership was influenced by gender with $\mathrm{p}=0.033$ and $\mathrm{OR}=2.74$ (95\% CI: 1.04-7.19). There was also a significant relationship between education level and membership of mutual health insurance with $\mathrm{p}=0.001$ and $\mathrm{OR}=3.71$ (95\% CI: 1.97-6.99). In the service offer, the quality of the medical prescription encouraged some people to join mutual health insurance with $\mathrm{p}=0.020$ and $\mathrm{OR}=2.12(95 \%$ CI: 1.12-4). Among the factors related to mutual health insurance, access to information about the existence of mutual health insurance influenced membership with $\mathrm{p}=0.001$ and $\mathrm{OR}=22.22$ (95\% CI: 3.01-163.84). This study not only revealed the low level of adherence to mutual health insurance in the Guediawaye health district, but also it helped identify the factors that positively or negatively influence adherence to mutual health insurance. With the involvement of all the actors concerned, such an information should make it possible to improve universal health coverage in the Guediawaye health district.
\end{abstract}

Keywords: Mutual Health Insurance, Determinants, Membership, Guediawaye District

\section{Introduction}

Financing health care continues to be a major challenge in the developing world. Despite efforts to improve the delivery of health services, many low-and middle-income countries are still far from achieving universal health coverage [9]. According to the Organization for Economic Co-operation and Development (OECD) report, 1.3 billion people lack access to effective and affordable health care.
In Africa, analyses of health reforms in recent decades all lead to the same conclusion: the equity aspect of public health policies has been neglected, and the primary concerns of the actors have focused on the effectiveness of the organization to be put in place $[2,12]$. Indeed, these policies (primary health care with Alma-Ata in 1978; cost recovery in the Bamako Initiative in 1987) have generalized the pricing of medical procedures and the sale of drugs, from basic care to hospital care. In the absence of health insurance or effective care for 
the poor, 93 per cent of poor urban households do not have health insurance [18]. These policies have, on the one hand, increased the availability of quality health care, but on the other hand, have made it difficult for a fraction of the population to access it $[11,13]$.

In this context, the search for viable sources of funding is becoming urgent. This situation weighs more heavily on the actors of the informal sector, who make up more than $80 \%$ of the active population in developing countries [14]. It is in this context that the initiation and impetus of mutuality in the dynamics of financing the health sector in Senegal emerged.

In Senegal, the advent of mutual insurance scheme in the health sector, at least in its current community-based formula, is relatively recent. The promotion of mutuality in the health sector has received political support through the establishment by the Ministry of Health, of a program of support for the development of mutual health insurance since 1997. At the end of 2003, Senegal had 79 functioning mutual health insurance funds [14]. In 2010, Senegal had more than 130 mutual health insurance services in operation [8]. In Senegal, in 2012 the coverage rate of the target population by mutual health insurance was $13.6 \%$ [15].

Mutual health insurance is a central point in the strategic plan for universal health coverage. However, currently mutual health insurances are not attractive, hence the low membership rate.

This study will contribute to the establishment of milestones for better access to health coverage, especially for indigent populations living in the informal sector.

The general objective of this study is to analyze the determinants of mutual health insurance membership in the Guédiawaye health district.

\section{Framework of the Study}

Located in the north suburban area of the Dakar region, the Guédiawaye health district comprises 12 public health posts in operation and one health center. The overall population census in 2013 estimates the total population of the district at 355,525 inhabitants in 2015; that is an average density of 12,688 inhabitants per $\mathrm{km}^{2}$. So, Guédiawaye is the most densely populated area at the national level. The lack of industrial and service activity zones means that the town of Guédiawaye is home to local economic activities, mainly informal activities. The main activities are trade and handicrafts. In terms of education, the department has three high schools, four public junior high schools and 47 elementary schools. The gross enrolment rate in 2006 was already $98.6 \%$.

\section{Methodology}

The study was cross-sectional, descriptive and analytical. The study took place during the period from 21 to 31 December 2015 in the district of Guédiawaye.

The study population consisted of all household heads residing in the Guédiawaye health district in 2015.

We included any household head:
1. Having at least one (1) dependent person.

2. And Residing for at least 3 months in the Guédiawaye health district.

Were not included in the study:

1. Any head of household missing on the day of the survey;

2. Any head of household refusing to participate in the survey.

\subsection{Sampling}

We conducted a two-stage survey. For the first stage, we used a random sample to draw the neighborhoods to be surveyed. The 2 nd stage included the houses. Once in the house, every head of household meeting the inclusion criteria were surveyed.

The house was a sampling unit.

Any household head residing in the Guédiawaye health district was a statistical unit.

The sample size was obtained using the Schwartz formula:

$$
\mathrm{n}=\left(\mathcal{E}^{2} \cdot \mathrm{p} \cdot \mathrm{q}\right) / \mathrm{i}^{2}
$$

For the study, a questionnaire was used to collect data from the heads of the households to be surveyed. This questionnaire was developed using a literature review and administered to the respondents (heads of household) during an interview in their homes. It was pre-tested with 20 heads of household in the health districts of Guédiawaye.

Interviewers trained in data collection techniques were responsible for conducting the survey. The questionnaires were administered by direct interview (home visits).

\subsection{Analysis}

The data collected were entered on electronic forms developed for this purpose with the Epi Info software. After a file cleaning, a statistical analysis was carried out using $\mathrm{R}$ 3.1.2 software.

The first step was a description of the different quantitative and qualitative variables collected (individual characteristics, resources, needs) in terms of position parameters (means, medians, frequencies) and dispersion parameters (standard deviation, extremes). Cross-tabulations between the independent variables with the dependent variable (membership of a mutual health insurance fund) were carried out to meet the expectations of the objectives concerning the identification of determinants. This was done using Chi-square tests according to their conditions of applicability, and the non-parametric Fisher test. The difference was found to be statistically significant when the $\mathrm{p}$ was less than 0.05 . The odds ratio was used to quantify the strength of the relationship.

\section{Ethical Considerations}

Respondents' consent was obtained in advance: Respondents were informed of the objectives and constraints of the study, their rights to refuse to participate in the study or to leave it at any time. Anonymity and confidentiality were 
respected.

\section{Results}

\subsection{Descriptive Part}

The mean age of the sample was 42.6 years with a standard deviation of 11.9 years. The maximum age was 85 years. Women represented $62 \%$ of the respondents (table 1 ). The average size of the households surveyed was 8.6 individuals with a standard deviation of 4.7 . In the sample, the number of persons in charge was less than 5 for $48 \%$ of the heads of households surveyed.

The monthly income of a household head was between CFAF 50,000 and 150,000 for 68\% (table 1). In the study, only
$25 \%$ of the respondents had been informed of the existence of a mutual health insurance and $13 \%$ of the household heads surveyed had some other form of health insurance.

The main reason for not joining a mutual health insurance scheme was lack of information on its existence, with $71.9 \%$ of respondents not having any information on the existence of such a scheme.

Reports about "Satisfactory" quality service was predominant in the study, ranging from $86 \%$ for quick diagnosis to $79 \%$ for drug availability and prescription. Reports on the welcoming quality accounted for $77 \%$.

The level of adherence of household heads to mutual health insurance was $11 \%$.

Table 1. Distribution of respondents according to their characteristics $(N=300)$.

\begin{tabular}{lll}
\hline Individual characteristics & Absolute frequency (n) & relative frequency \\
\hline Educational background & & 24 \\
Primary & 71 & 24 \\
High School & 73 & 13 \\
Higher education & 39 & 39 \\
None & 117 & \\
Occupation & 72 & 24 \\
Jobless & 59 & 20 \\
Employee & 129 & 43 \\
Merchant & 40 & 13 \\
Other & & \\
Therapeutic resort & 289 & 96 \\
Health structure & 3 & 1 \\
Self-medication, & 3 & 1 \\
Traditional healer & 5 & 2 \\
DSDOM & & \\
Marital Status & 50 & 17 \\
Single & 210 & 70 \\
Married & 8 & 3 \\
Divorced & 32 & 10 \\
Widowed & & \\
Membership to an association & 119 & 40 \\
Yes & 181 & 60 \\
No & 67 & 22 \\
Head of household's income & 205 & 68 \\
Less than 50,000 & 28 & 10 \\
50,000 to 150,000 FCFA & & \\
More than 150 FCFA & & \\
\hline & & \\
\hline
\end{tabular}

\subsection{Analytical Part}

The proportion of male household heads was $21.2 \%$, while the proportion of female heads of household was $4.8 \%$ among mutual insurance members $(p<0.001)$. Male heads of households were 5.3 times more likely to be members of a health insurance plan. Educated household heads, as well as those with an occupation, were 5.2 times more likely to be members of a mutual health insurance scheme $(p=0.001)$ and polygamous household heads $(\mathrm{OR}=4.7)$. household Heads belonging to an associative movement were 20.0 times more likely to belong to a mutual health insurance scheme (Table 2).

Thus, gender, education, occupation, marital status (polygamy) and membership in an association movement were identified as factors favoring membership of a mutual insurance company.

Heads of middle-and high-income households were 4.9 times more likely to join a mutual health insurance scheme. The same was true for heads of households who were informed of the existence of a mutual health insurance scheme in their areas $(p<0.001)$, heads of households with another form of health insurance were $(\mathrm{OR}=61.06)$, household heads finding satisfactory reception in health structures were $(\mathrm{OR}=10.7)$ and finally household heads finding satisfactory prescription of medicines in health structures were $(\mathrm{OR}=9.8)$ (Table 2).

However, age, therapeutic use, household size, number of dependents, and past membership in an association were not significantly related to membership in a mutual health insurance scheme. 
Table 2. Characteristics of household heads according to membership of the mutual health insurance.

\begin{tabular}{|c|c|c|c|c|}
\hline CHARACTERISTICS & Number & Membership (\%) & P-Value & Odds Ratio (OR) (95\%CI) \\
\hline \multicolumn{5}{|l|}{ Gender } \\
\hline Male & 113 & 21.2 & $<0.001$ & $5.3[2.2-13.5]$ \\
\hline Female & 187 & 4.8 & & \\
\hline \multicolumn{5}{|l|}{ Educational background } \\
\hline Educated & 183 & 15.8 & 0.001 & $5.2[1.7-21.3]$ \\
\hline Not educated & 117 & 3.4 & & \\
\hline \multicolumn{5}{|l|}{ Occupation } \\
\hline Having a job & 228 & 14.5 & 0.001 & Ind. \\
\hline jobless & 72 & 0 & & \\
\hline \multicolumn{5}{|l|}{ Matrimonial system } \\
\hline Monogamy & 132 & 6.8 & $<0.001$ & $4.7[1.9-12.5]$ \\
\hline Polygamy & 81 & 25.9 & & \\
\hline \multicolumn{5}{|c|}{ Membership of an Association } \\
\hline YES & 119 & 25.2 & $<0.001$ & $20.0[5.9-104.3]$ \\
\hline NO & 181 & 1.7 & & \\
\hline \multicolumn{5}{|c|}{ Access to information: Existence of a mutual health insurance in the whereabouts } \\
\hline YES & 75 & 44.0 & $<0.001$ & Ind. \\
\hline NO & 225 & 0.0 & & \\
\hline \multicolumn{5}{|c|}{ Existence of other forms of health insurance } \\
\hline YES & 38 & 65.8 & $<0.001$ & $61.0[21.1-183.8]$ \\
\hline NO & 262 & 3.1 & & \\
\hline \multicolumn{5}{|c|}{ Appreciation of welcoming conditions } \\
\hline Satisfied & 232 & 13.8 & 0.008 & $10.7[1.7-442.0]$ \\
\hline Not satisfied & 68 & 1.5 & & \\
\hline \multicolumn{5}{|c|}{ Appreciation of Drug Prescription } \\
\hline Satisfied & 236 & 13.6 & 0.012 & $9.8[1.5-407.9]$ \\
\hline Not satisfied & 64 & 1.6 & & \\
\hline \multicolumn{5}{|l|}{ Dependent people } \\
\hline$\leq 10$ & 112 & 11.6 & 0.945 & - \\
\hline More than 10 & 188 & 20.0 & & \\
\hline \multicolumn{5}{|l|}{ Age } \\
\hline Under 60 & 270 & 11.9 & 0.268 & - \\
\hline 60 years old and over & 30 & 3.3 Bha & & \\
\hline \multicolumn{5}{|c|}{ Appreciation of Drug Availability } \\
\hline Satisfied & 238 & 12.6 & 0.130 & - \\
\hline Not satisfied & 62 & 4.8 & & \\
\hline
\end{tabular}

\section{Discussion}

Household Heads who had joined a mutual health insurance scheme at the time of the survey represented $11 \%$. The study shows that gender, level of education, occupation, marital status, membership of an association, income, appreciation of welcoming conditions, appreciation of drug prescription, access to information on the existence of a mutual health insurance and the fact of having another health insurance were associated with membership of a mutual health insurance.

The prevalence of membership of a mutual health insurance scheme in the study is below the national rate of $13.6 \%$, but does not reach the rate of which is $50.50 \%$ targeted by the National Strategy for Economic and Social Development (NSESD 2013-2017) [15]. This low rate could be explained by the fact that the mutual health insurance union is newly created in Guediawaye.

In the study, male household heads are more likely to be members of a mutual health insurance. This result corroborates the study by Dong et al. in Burkina Faso where men are willing to pay more than women for a mutual health insurance scheme [8]. This may be due to the fact that women have a lower level of education, lower incomes and higher marriage rates than men.

The study showed that there is no link between age and membership. Results are noted by Dubois, who found a significant number of older people (over 60 years old) among mutualists [10]. Criel reports the fact that older people are more economically and socially excluded from the community and therefore find it more difficult to participate in mutual health insurance [3]. Similarly, Dong et al. find that older people would be willing to pay less than younger people for a mutual health insurance scheme [7].

In the study, the occupation of the household head seems to influence the decision whether or not to join a mutual health insurance scheme. Employed household heads are more likely to join a mutual health insurance scheme than unemployed ones. This result does not corroborate with that of other studies $[6,16]$.

Studies $[5,8,10]$ show that education influences participation in a mutual health insurance scheme, with a higher level of education favouring membership. Jütting's study in Senegal indicates that the higher the level of education, the greater the probability of joining a mutual health insurance scheme when measured in terms of years of schooling or literacy skills [6]. Thus, among the population 
covered by the study, $15.8 \%$ of educated household heads are more likely to join a mutual health insurance scheme than their uneducated peers. This result could be explained by the fact that individuals with formal education would pay greater attention to health risks, be more open to innovation and have greater ability to understand the benefits of the mutual health insurance system.

The study showed that the matrimonial regime is associated with membership to a mutual health insurance scheme. Indeed, the proportion of polygamists among mutualists is higher than that of monogamists. This could be explained by the high proportion (95\%) of Muslims in Guédiawaye, as Islam encourages polygamy. Dubois also points out that, among mutualists, the proportions of monogamous and polygamous households are relatively similar and close to national statistics [10].

Conversely, membership in the past of an association does not seem to influence the decision to join a mutual health insurance in the study. Studies [1, 17] have shown that previous negative experiences can alter people's confidence and constitute a barrier to joining a mutual health insurance scheme.

The level of household income appears to be an essential parameter of membership in the study. Indeed, household heads with medium and high incomes are more likely to join a mutual health insurance scheme. Moreover, several studies [6, 16] show that the socio-economic level of members is higher than that of non-members.

The study showed that information seems to influence the decision to join a mutual health insurance service. Indeed, the proportion of people who have been informed of the existence of a mutual health insurance service in their area is high (44\%). This result could be explained by the lack of awareness at the local level despite an ideal setting of a youth center opposite the health center,

The study showed that there is a link between having another health insurance and joining a mutual insurance service. Indeed, the proportion of people with other health insurance among members is high $(65.8 \%)$ in the study. This could be explained by the fact that those with other health insurance are aware of the advantages of mutual insurance and therefore readily accept them.

The study showed that the reception and prescription of medicines seem to influence the decision to join a mutual health insurance scheme, as opposed to the availability of medicines and the speed of the diagnosis result. Some studies state that the main criticisms expressed by members are the poor quality of the medicines prescribed [4] and stock-outs of products [1], others mention that the dissatisfaction of beneficiaries is more related to over-prescription of medicines and the way health workers treat patients differently according to their socio-economic status $[17,5]$.

Thus, poor quality of health care provision appears to be a major factor in non-adherence and an important reason for disaffiliation from a mutual health insurance scheme.

\section{Conclusion}

Mutual health insurance is one of the main ways to universal health coverage and contributes to the achievement of one of the sustainable development objectives. Among the challenges facing mutual health insurance, the issue of membership currently appears to be predominant. This study shows the importance of a set of factors that should be taken into account to improve people's membership of mutual health insurance.

\section{References}

[1] Basaza R, Criel B, Van Der Stuyft P. Community health insurance in Uganda: Why does enrolment remain low? A view from beneath. Health Policy. 2008. 87: 172-184 p.

[2] Cisse B, Luchini S, Moatti Jp. Les effets des politiques de recouvrement des coûts sur la demande de soins dans les Pays en Développement: les raisons de résultats contradictoires. Revue française d'économie. 2004. 111-149 p.

[3] Criel B. District-based health insurance in sub-Saharan Africa, Part II: Case-studies. Studies in Health Services Organisation and Policy. Anvers, Belgique. 1998. 9 p.

[4] Criel B, Barry A, Von Roenne F. Le projet PRIMA en Guinée Conakry. Une expérience d'organisation de mutuelles de santé en Afrique rurale. Bruxelles, Belgique: Medicus Mundi. 2002.

[5] De Allegri M, Sanon M, Sauerborn R. To enrol or not enrol. A qualitative investigation of demand for health insurance in rural West Africa. Social Science Medicine. London: Brunel University; 2006a. 62: 1520-1527 p.

[6] De Allegri M, Kouyaté B, Becker H, Gbangou A. Understanding enrolment in community health insurance in sub-Saharan Africa: a population-based case-control study in rural Burkina Faso. Bulletin World Health Organisation. 2006b. 84: $852-858 \mathrm{p}$.

[7] Diop F, Ba A. Mutual Health Insurance, Scaling-Up and the Expansion of Health Insurance in Africa. Bethesda, Maryland: Health Systems 20/20, 2010.

[8] Dong H, kouyate B, Snow R, Mugisha F, Sauerborn R. Gender's effect on willingness-to-pay for community-based insurance in Burkina Faso. Health Policy. 2003. 64: 153-162 p.

[9] Drechsler D, Jütting J. Private Health Insurance for the Poor in Developing Countries? OECD Development Centre. 2005. 11: $7 \mathrm{p}$.

[10] Dubois F. Les déterminants de la participation aux mutuelles de santé: Etude appliquée à la mutuelle LeeréLaafiBolem de Zabré: Mémoire de fin d'étude. Belgique: Université de Liège, DES en Gestion du développement. 2002.

[11] Forsythe S. Assessing the Cost and Willingness to Pay for Voluntary HIV Counselling and Testing in Kenya. Health Policy Planning. 2002.187-195 p.

[12] Gilson L, Doherty J, Loewenson R, Francis V. Challenging inequity through health systems. Final report of Knowledge Network on Health Systems. Geneva: WHO. Commission on the Social Determinants of Health. 2007. 
[13] Mariko M. Quality of Care and the Demand for Health Services in Bamako, Mali: The Specific Roles of Structural, Process and Outcome Components. Social Science \& Medicine. 2003. 1183-1196 p.

[14] Ministère de la santé et de l'action sociale. Plan stratégique de développement des mutuelles de santé au Sénégal. MSAS. 2004. $82 \mathrm{p}$.

[15] Ministère de la santé et de l'action sociale. Plan stratégique de développement de la couverture maladie universelle au Sénégal 2013-2017. MSAS. 125 p

[16] Musango L, Martiny P, Porignon D, Dujardin B. Le profil des membres et des non membres des mutuelles de santé du
Rwanda: le cas du district sanitaire de Kabutare. Cahier de santé. 2004. 14: 93-99 p.

[17] Schneider P. Trust in micro-health insurance: an exploratory study in Rwanda. Social Science \& Medicine. 2005. 61: 1430-1438 p.

[18] UNICEF, Coopération Française, GOBBERS D. Qualité et accès aux soins en milieu urbain: résultats de la recherche menée dans cinq capitales d'Afrique de l'Ouest. Rapport UNICEF. 2000

[19] Waelkens M-P, Criel B. Les mutuelles de santé en Afrique subsaharienne. État des lieux et réflexions sur un agenda de recherche. Health Nutrition and Population (HNP). Banque mondiale: Washington DC. 2004. 124 p. 